\title{
X-Ray Fluorescence Determination of Trace Gold in an Ion-Exchange Resin
}

\author{
I. F. Mikhailov, A. A. Baturin, A. I. Mikhailov, and L. P. Fomina \\ National Technical University Kharkiv Polytechnic Institute, Kharkiv, 61002 Ukraine \\ e-mail: m_if@ukr.net \\ Received March 13, 2012
}

\begin{abstract}
The use of portable X-ray optics with a secondary radiator in the determination of trace gold in an ion-exchange resin within the mass fraction range of $1-50 \mathrm{ppm}$ is described. It is shown that the secondary radiator design with primary radiation filtering allows one to determine trace gold in an ion-exchange resin when the mass fraction of gold is lower than $1 \mathrm{ppm}$.
\end{abstract}

Keywords: X-ray fluorescence analysis, secondary radiator, trace impurities, calibration characteristic, detection limit

DOI: $10.1134 / \mathrm{S} 002016851414009 \mathrm{X}$

The rapidity of determining trace precious metals in a low-density filler is a rather important parameter of the measurement methods used in processing certain raw materials. X-ray fluorescence (XRF) analysis is one of the better known methods for determining trace impurities and is valued as a relatively simple and nondestructive express method that does not require complicated sample preparation. The use of standard XRF analysis setups for determining trace precious metals is complicated by a strong scattered radiation background: the detection limit for trace impurities is 50-200 ppm, while it is necessary to determine the content of impurities as low as $1-10 \mathrm{ppm}$. Significant advances in determining trace quantities of precious metals were made with the use of polarized radiation designs where the detection limit $C_{\min } \approx 1 \mathrm{ppm}[1,2]$. However, these designs require complex collimation devices and intense primary radiation sources $(\sim 1 \mathrm{~kW})$, and the spectrometers utilizing these designs are bulky and expensive [3]. It was shown in [4] that a high peak-to-background ratio in the spectra may be obtained even in a simple design with a secondary radiator if it is multilayered with an optimal combination of the absorber and radiator functions.

The present study is aimed at reducing the gold detection limit in the $\mathrm{X}$-ray fluorescence analysis of an ion-exchange resin to lower than $1 \mathrm{ppm}$ through the use of portable X-ray optics with a secondary radiator [4].

The objects under study were reference samples of gold in an ion-exchange resin with the gold content of $200,50,20,10$, and $0 \mathrm{ppm}$. The samples in the form of spheres with diameters on the order of $1 \mathrm{~mm}$ were arranged in a single layer on 3525 ULTRALENE (SPEX SamplePrep) ultrathin films.
The measurements were conducted using a Sprut-K (AO Ukrrentgen) energy-dispersion spectrometer with an X-100 (Amptek) Si(Li) detector. The measurement design is shown in Fig. 1. The BS-22 X-ray tube with a through-type silver target (1) irradiates the yttrium secondary radiator (3) through the $60-\mu \mathrm{m}$-thick primary radiation filter made of silicon (2). The fluorescence radiation from the reradiator passes through the slit (4), reaches the sample surface (5), and excites the impurity atoms, the analytical lines of which are recorded by the detector (7). The scattering angle $2 \Theta \approx 100^{\circ}$, and the aperture of this design is $8 \times$ $10^{-6}$ (X-ray target-radiator, radiator-sample, and sample-detector). The $\mathrm{X}$-ray tube operating regime is as follows: $U=35 \mathrm{kV}, I=250 \mu \mathrm{A}$, and the exposure time is $600 \mathrm{~s}$.

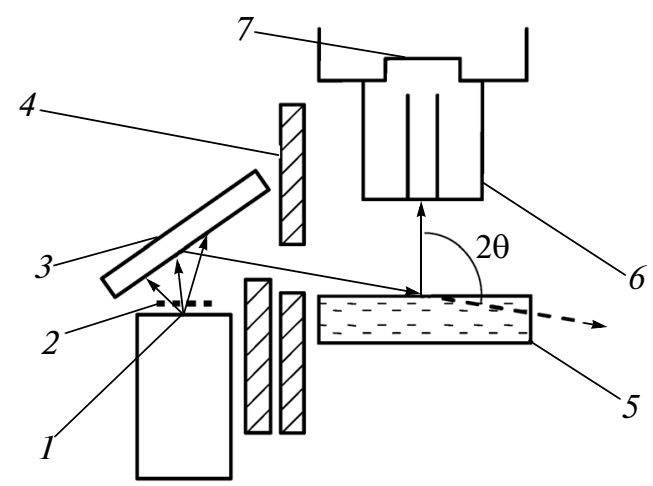

Fig. 1. X-ray optics measurement design. The collimator is denoted by 6 . The other designations are given in the text. 


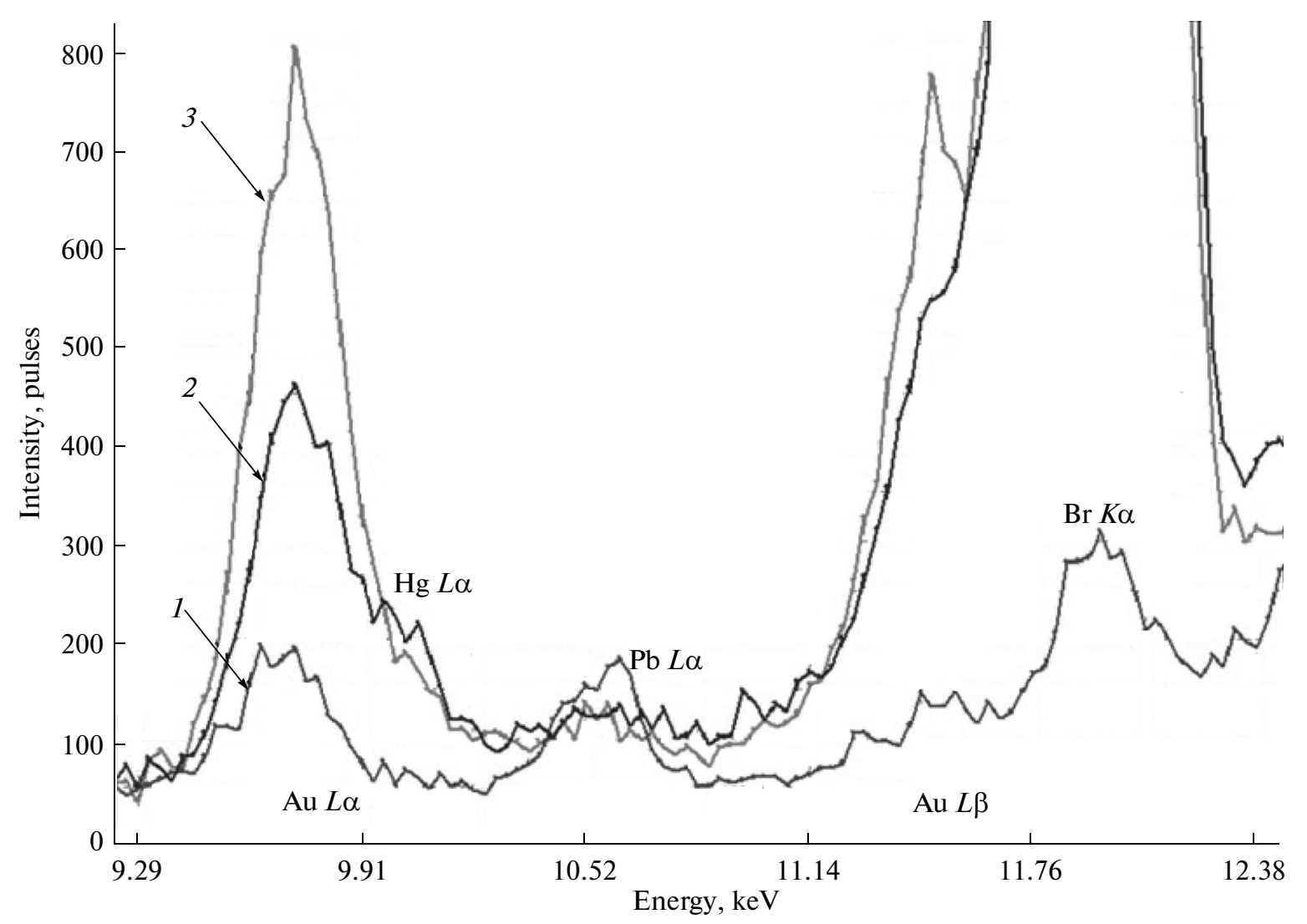

Fig. 2. Part of the spectrum of reference samples with trace gold impurities. The gold content is (1) 10, (2) 20, and (3) 50 ppm. The secondary radiator is made of yttrium. The exposure time is $600 \mathrm{~s}$.

Figure 2 shows a part of the typical X-ray fluorescence spectrum of a reference sample of gold in an ion-exchange resin. The integral intensity of the $\mathrm{Au}$ $L \alpha$ line was determined as the area below the curve by summing the pulses accumulated in the corresponding spectrometer channels, and the background was measured by summing the pulses in the same channels in the spectrum of a blank sample.

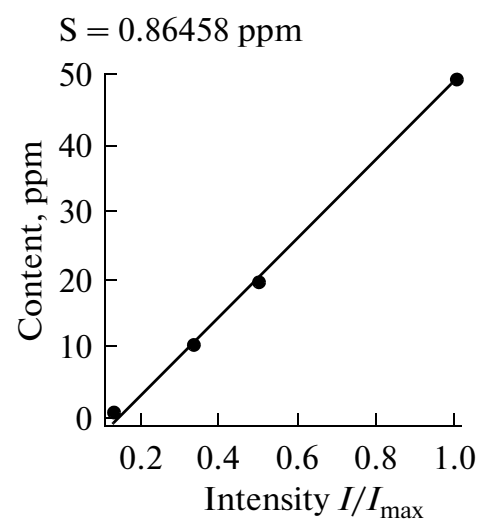

Fig. 3. Calibration characteristic for determining the gold content in an ion-exchange resin based on the integral intensity of the Au $L \alpha$ line. The exposure time is $600 \mathrm{~s}$.
As the gold content is reduced, the $\mathrm{Au} L \alpha$ line intensity decreases steadily. Unfortunately, the reference samples contained other trace impurities $(\mathrm{Br}, \mathrm{Pb}$, and $\mathrm{Hg}$ ), and their content was not rated. The lines of these impurities are superimposed onto the $\mathrm{Au} L \beta$ line and interfere with the measurement of its intensity. However, the Au $L \alpha$ line intensity could be measured reliably in all the samples except for the one with the gold mass fraction of $20 \mathrm{ppm}$. A weak $\mathrm{Hg} L \alpha$ line was superimposed onto the $\mathrm{Au} L \alpha$ line in the spectrum of this sample, and the contribution from the $\mathrm{Hg} L \alpha$ line to the intensity of the line of the element under analysis was taken into account using the full-profile spectrum analysis software supplied with the spectrometer.

When the gold content is $10 \mathrm{ppm}$, the peak-tobackground ratio for the $\mathrm{Au} L \alpha$ line is 4.2. This allows one to determine the content of trace precious metals with the use of the calibration characteristic method starting with the gold content of $0.5 \mathrm{ppm}$ (if the corresponding reference samples are available).

Figure 3 shows the calibration characteristic for determining the gold content in an ion-exchange resin (the monitoring signal is the integral intensity of the yttrium reradiator $K \alpha$ and $K \beta$ lines scattered by the sample). The standard deviation of the calibration function $S$ is $0.86 \mathrm{ppm}$ within the gold mass fraction range of $0-50 \mathrm{ppm}$. The sensitivity $\partial N / \partial C$ determined 
on the basis of the integral intensity of the Au $L \alpha$ line is 105 pulses/ppm. The background signal in a blank experiment is 1100 pulses. Therefore, the detection limit according to the $3 \sigma$ criterion is $0.95 \mathrm{ppm}$. Regardless of this detection limit estimate based on the formal criterion, the obtained peak-to-background ratio ensures the signal detection for samples with a gold mass fraction of $0.5 \mathrm{ppm}$.

Thus, the secondary radiator design with primary radiation filtering allows one to determine trace gold in an ion-exchange resin when the mass fraction of gold is lower than $1 \mathrm{ppm}$.

\section{ACKNOWLEDGMENTS}

The authors would like to thank Elvateh Ltd. for providing the reference samples.

\section{REFERENCES}

1. Verigin, A.A., Naumik, A.I., and Madzhara, E.O., Determining the gold content in solutions and ionexchange resins via the energy-dispersive X-ray analysis. Paper presented at the VII Conference "Siberia and the Far East Analytics," Novosibirsk, October 2004.

2. Verigin, A.A. and Petrov, V.A., The analysis of industrial operation of the SRV X-ray spectrometers in Kazakhstan, Anal. Kontrol, 2002, vol. 6, no. 4, p. 470.

3. Heckel, J. and Ryon, R.W., Handbook of X-Ray Spectrometry, Van Grieken, E. and Markowicz, A., Eds., CRC Press, 2001, 2nd ed., ch. 10, pp. 603-630.

4. Mikhailov, I.F., Baturin, A.A., Mikhailov, A.I., and Borisova, S.S., Contrast enhancement of X-ray fluorescence spectra using the secondary two-layer radiator, Funct. Mater., 2011, vol. 18, no. 2, pp. 150-155.

Translated by D. Safin 